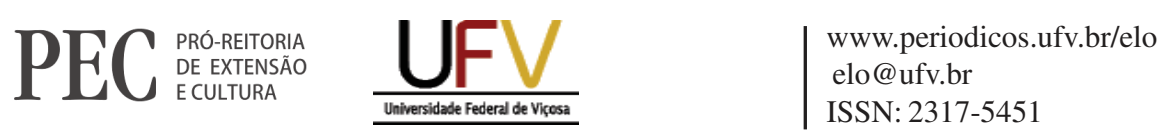

\title{
NAF: um projeto de extensão que contribui para o desenvolvimento de estudantes, sociedade e instituições públicas
}

\author{
Geysa Gabriela Pinheiro Gomes ${ }^{1}$, Hugo Azevedo \\ Rangel de Morais $^{2}$, Ricardo Aladim Monteiro ${ }^{3}$
}

\begin{abstract}
Resumo: $O$ "Núcleo de Apoio Contábil e Fiscal da UFCA" é um projeto de extensão criado em 2019. O objetivo desse relato é descrever as atividades desenvolvidas pelo projeto de extensão NAF. Inicialmente, foram realizados treinamentos ofertados pela Receita Federal, SEFAZ-CE e pelo professor orientador para a capacitação dos discentes. Também realizou-se reuniões para a organização do projeto. Logo após, começaram os atendimentos para a sociedade. Percebeu-se que houve bastante participação dos alunos, aumento de suas relações interpessoais e melhoria na comunicação. Assim, identificou-se que o projeto é de grande relevância para todos os envolvidos.
\end{abstract}

Palavras-chave: Educação fiscal. Extensão. Projeto NAF.

Área Temática: Educação.

\section{NAF: an extension project that contributes to the development of students, society and public institutions}

\begin{abstract}
The "UFCA Accounting and Tax Support Center" is an extension project created in 2019. The purpose of this report is to describe the activities developed by the NAF extension project. Initially, training was offered by the Federal Revenue Service, SEFAZ-CE and by the advisor teacher for the training of students. Meetings were also held to organize the project. Soon after, assistance to society began. It was noticed that there was a lot of student participation, increased interpersonal relationships and improved communication. Thus, it was identified that the project is of great relevance for all involved.
\end{abstract}

Keywords: Fiscal education. Extension. NAF Project.

\section{NAF: un proyecto de extensión que contribuye al desarrollo de estudiantes, sociedad e instituciones públicas}

Resumen: El "Centro de Apoyo Contable y Fiscal de la UFCA" es un proyecto de extensión creado en 2019. El propósito de este informe es describir las actividades desarrolladas por el proyecto de extensión NAF. Inicialmente, la capacitación fue ofrecida por el Servicio de Ingresos Federales, SEFAZ-CE y por el maestro asesor para la formación de estudiantes. También se realizaron reuniones para organizar el proyecto. Poco después comenzó la asistencia a la sociedad. Se notó que hubo mucha participación de los estudiantes, aumento de las relaciones interpersonales y mejor comunicación. Así, se identificó que el proyecto es de gran relevancia para todos los involucrados.

Palabras clave: Educación fiscal. Extensión. Proyecto NAF.

\footnotetext{
${ }^{1}$ Graduanda em Ciências Contábeis pela Universidade Federal do Cariri - UFCA. Rua Coronel Francisco Nery - 604, Juazeiro do Norte - CE. Contato: (88) 988133713. E-mail: geysapinheiro0@gmail.com.

${ }^{2}$ Mestre em Administração pela Universidade Federal do Rio Grande do Norte - UFRN. Professor do Centro de Ciências Sociais e Aplicas da Universidade Federal do Cariri. Juazeiro do Norte - CE.

${ }^{3}$ Mestre em Administração pela Universidade de Potiguar - UnP. Professor do Centro de Ciências Sociais e Aplicas da Universidade Federal do Cariri. Juazeiro do Norte-CE.
} 


\section{INTRODUÇÃO}

Criado em 2011, o Núcleo de Apoio Contábil e Fiscal (NAF) é um projeto desenvolvido pela Receita Federal Brasileira (RFB) em parceria com as Instituições de Ensino Superior (IES), contemplando os cursos de Ciências Contábeis e Comércio Exterior. De acordo com a Receita Federal Brasileira (2020), o projeto tem como objetivo geral oferecer serviços contábeis e fiscais gratuitos para pessoas físicas e jurídicas de menor poder aquisitivo e como objetivos específicos propagar a educação fiscal na sociedade, apresentar o sistema de arrecadação tributária e unir a teoria estudada em sala de aula com a prática no atendimento a sociedade.

A educação fiscal é importante para conscientizar a sociedade sobre seus direitos e deveres fiscais (BRASIL, 2020). Tem-se uma perspectiva de que os tributos pagos não são utilizados corretamente e, consequentemente, não obtém os benefícios devidos (GRZYBOVSKI; HAHN, 2006). Desse modo, o cidadão adquire o conhecimento necessário para compreender desde a arrecadação até a aplicação dos tributos. Para isso, o projeto também tem parceria com a Secretaria da Fazenda do Ceará - SEFAZ - CE.

Assim como a sociedade, os alunos e as instituições de ensino também são beneficiadas. Os estudantes unem os conteúdos abordados em sala de aula com as práticas desenvolvidas pelo projeto, ganham treinamentos da RFB, SEFAZ-CE e do professor orientador, aprendem a trabalhar em equipe, obtém maior conhecimento e experiência para o mercado de trabalho. Segundo Moreira et al. (2015) o mercado de trabalho não exige apenas competências exclusivas da profissão, mas também habilidades que o tornem um profissional diferente dos demais e, que para isso, é necessária uma formação qualificada. As instituições de ensino formam melhores profissionais e aumentam o desenvolvimento social. Isso acontece por meio da extensão universitária que proporciona uma relação entre a universidade e a sociedade e, a partir dessa vivência, tanto os discentes como os docentes adquirem mais conhecimentos (KOGLIN; KOGLIN, 2019).

O NAF UFCA iniciou seu funcionamento no segundo semestre de 2019, com a participação de 11 alunos voluntários. Este projeto está vinculado ao Núcleo de Práticas Contábeis. Inicialmente, os serviços oferecidos foram: orientação e elaboração de Declaração de Imposto de Renda; abertura, acompanhamento e encerramento do Microempreendedor Individual - MEI; emissão de certidão negativa, regularização do Cadastro da Pessoa Física-CPF; orientação e emissão de carteira de trabalho digital. A partir disso, a sociedade passou a ter mais uma opção de auxílio para resolver questões relacionadas a assuntos fiscais e contábeis.

\section{OBJETIVOS}

O presente trabalho busca descrever as atividades desenvolvidas pelo projeto de extensão "Núcleo de Apoio Contábil e Fiscal -NAF" da UFCA. Assim, mostrando a importante contribuição que traz para a sociedade, estudantes, instituição de ensino, Receita Federal Brasileira e Secretária da Fazenda do Ceará. 


\section{METODOLOGIA}

O projeto de extensão "Núcleo de Apoio Contábil e Fiscal” teve início em julho de 2019, quando assinou o termo de colaboração com a Receita Federal do Brasil. Em seguida, o coordenador do projeto apresentou aos 11 alunos voluntários a plataforma Cuboz, uma rede para alunos e coordenadores que fazem parte do projeto NAF. Essa plataforma disponibiliza cursos, artigos e webinars sobre esses assuntos contábeis e fiscais. Logo após, no primeiro semestre de 2019, ocorreu um treinamento ministrado pelo auditor fiscal da Receita Federal do Brasil, que também é coordenador de todos os NAFs da região do Cariri, sobre a situação cadastral do CPF. Depois, houve outra capacitação aplicada pelo professor orientador sobre o MEI. Os alunos também receberam treinamento da SEFAZ-CE sobre tributação e educação fiscal. Na sequência, realizou-se uma reunião com todos os extensionistas, docentes e entidades parceiras para a organização do funcionamento do NAF. No segundo semestre de 2019, o NAF UFCA começou a funcionar no centro de atendimento, localizado no Vapt Vupt de Juazeiro do Norte, situado no centro da cidade, local de fácil acesso a população. Funcionando de segunda-feira a sexta-feira, pela manhã das 8:00h às 12:00h e a tarde das 12:30h às 16:30h. Desse modo, cada um dos estudantes voluntários ficou responsável pelos atendimentos a população dois dias na semana. Para fins de divulgação, foi realizada entrevista para a TV Verde Vale, Rádio CBN e para a DCOM (Diretoria de Comunicação) da UFCA explicando os serviços gratuitos oferecidos pelo projeto para a população interna e externa. Além disso, os alunos envolvidos propagaram nas salas de aulas dos demais cursos da instituição. Também foi realizada uma ação de divulgação e orientação na emissão da carteira de trabalho digital no Campus Crato da UFCA. Ademais, participou da UFCA itinerante na cidade de Mauriti, que é uma ação de extensão que tem como objetivo realizar as atividades oferecidas pela UFCA para além das regiões Crato, Juazeiro do Norte e Barbalha-CRAJUBAR (PORTAL UFCA, 2020).

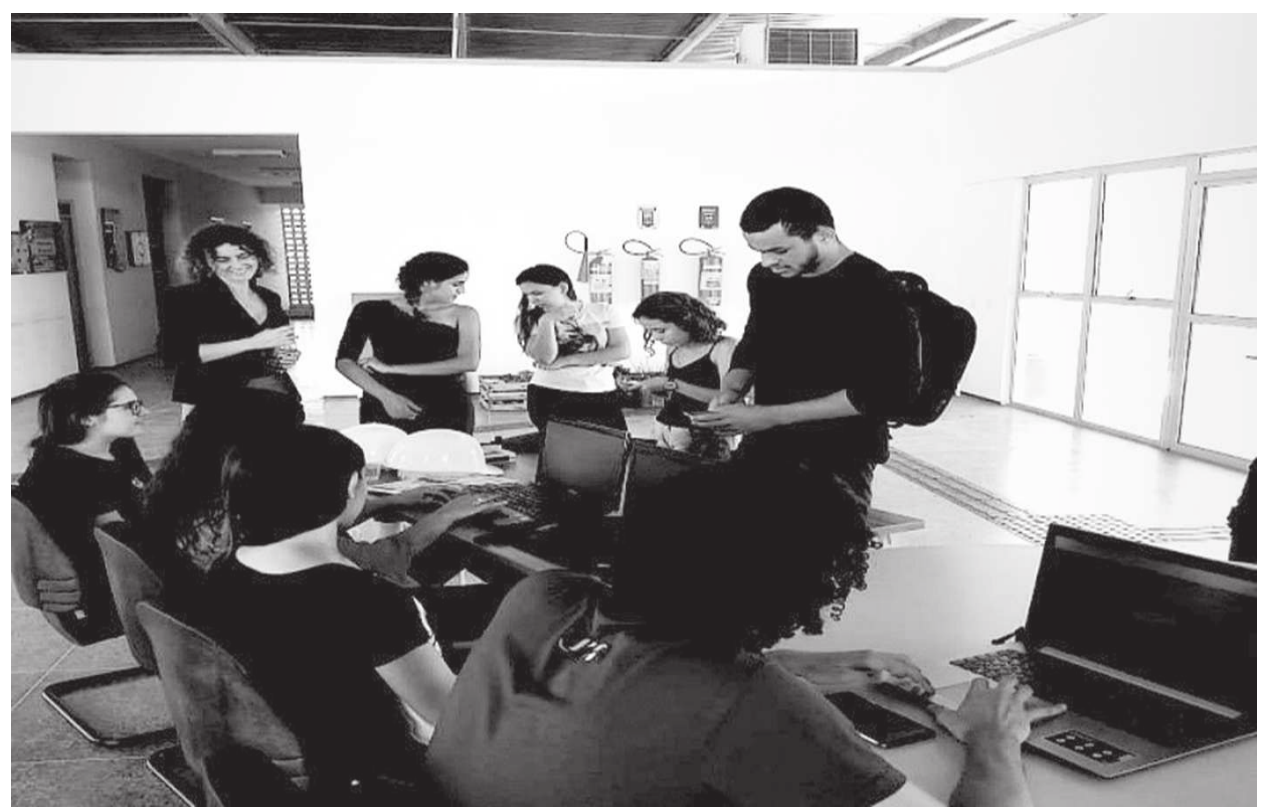

Figura 1 - Atendimento aos alunos do Campus Crato da UFCA.

Fonte: Arquivo das autoras. 


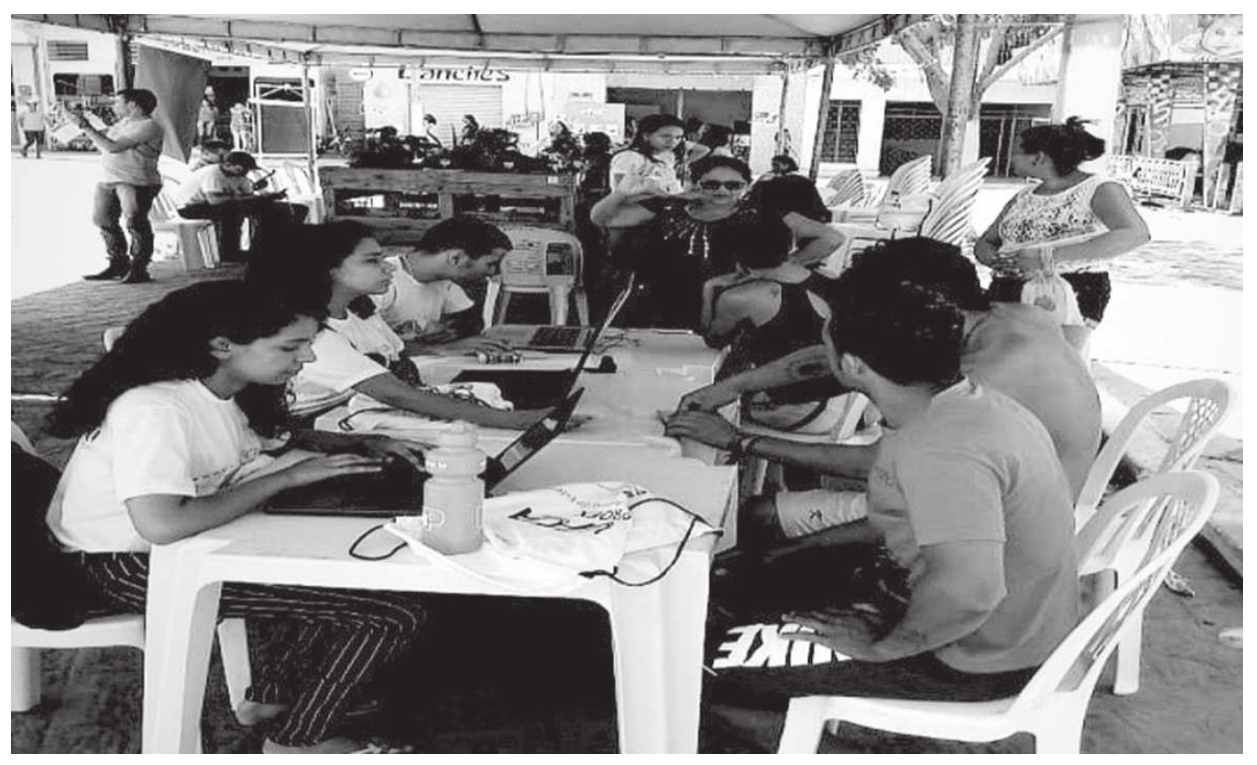

Figura 2 - Atendimento à população de Mauriti na ação de extensão UFCA itinerante. Fonte: Arquivo das autoras.

Em busca de conhecer as demandas da população do cariri com relação às necessidades contábeis, fiscais e trabalhistas, o NAF realizou uma pesquisa de campo no Mercado Pirajá de Juazeiro do Norte-CE por meio de um questionário fechado aplicado com os feirantes e camelôs. Em 2020, ocorreu um curso ministrado pela Receita Federal do Brasil, com duração de 3 dias, para todos os estudantes dos NAFs do Cariri sobre Imposto de Renda da Pessoa Física 2020. A partir disso, o NAF UFCA começou a oferecer mais esse serviço gratuito de orientação e elaboração de Declaração de Imposto de Renda. Contudo, foi estabelecido requisitos para verificar se o indivíduo está apto a participar do projeto, tendo em vista que o intuito não é substituir os escritórios de contabilidade. Para ser atendido pelo projeto o contribuinte deveria ter recebido rendimentos no ano-calendário 2019 de até R \$ 40 mil ou, caso seja aluno ou servidor da UFCA não há limite de renda, bastando apenas atestar com o comprovante de matrícula. Em março de 2020, começou no Brasil a pandemia do novo coronavírus (COVID-19), uma doença infecciosa. Para conter o contágio, a Organização Mundial da Saúde recomendou o distanciamento social. Logo, estabelecimentos não essenciais foram fechados. Assim, as atividades do projeto também foram suspensas presencialmente. Porém, para não deixar de oferecer os serviços, o NAF UFCA inovou e criou mecanismos para continuar o atendimento de forma remota através de e-mail, whatsApp, instagram e facebook. O projeto ainda incluiu na lista de serviços prestados a orientação sobre o Auxílio Emergencial que é um benefício financeiro para trabalhadores informais, microempreendedores individuais (MEI), autônomos e desempregados, para ajudar a sociedade nesse momento de crise econômica devido a pandemia do coronavírus (CAIXA ECONÔMICA FEDERAL, 2020). Para obter os serviços, a pessoa deve acessar os canais sociais do programa, como e-mail, instagram ou whatsapp. Em relação a Declaração de Imposto de Renda, foi feita uma lista de documentos necessários para o envio da declaração e também uma declaração de responsabilidade. Desse modo, o indivíduo confirma que está de acordo com todas as informações preenchidas 
na declaração, evitando assim possíveis problemas e questionamentos futuros. Ao iniciar o serviço de orientação sobre o Auxílio Emergencial, firmou-se uma parceria com o Programa de Voluntariado da Classe Contábil do Rio Grande do Norte (PVCC/RN) integrado ao Conselho Regional de Contabilidade do Rio Grande do Norte (CRC/RN). O PVCC RN criou também um canal chamado "Fale Fácil” para tirar dúvidas sobre o Auxílio Emergencial. Uma aluna do NAF, também é integrante desse programa, para que assim, possam trocar conhecimentos sobre o tema tratado. Portanto, observa-se que o NAF UFCA ultrapassou fronteiras, pois atendeu contribuintes tanto do Ceará como de outros estados.

\section{RESULTADOS E DISCUSSÃO}

De forma geral, observou-se grande participação dos discentes nas atividades propostas. Em média, 25 alunos do Curso de Ciências Contábeis da UFCA inscreviam-se nas capacitações, o que corresponde a 62,5\% do total de 40 alunos. Principalmente, porque foi oferecido um treinamento para além das disciplinas da graduação. Do ponto de vista de Souza et al. (2018) os profissionais da área contábil necessitam de conhecimento prático, para uma atuação correta e que supra com as exigências do mercado de trabalho. Percebeu-se que ao iniciar os trabalhos de divulgação, alguns integrantes começaram a desenvolver melhor sua oratória. Loyola e Paiva (2017, p. 243) alega que:

a comunicação tornou-se um instrumento de integração, instrução e trocas. Atualmente vem ganhando uma significativa importância, sendo cada vez mais pautada na sociedade e, principalmente nas organizações. (LOYOLA, PAIVA, 2017).

Vale ressaltar que, isso é importante para prestar os serviços com excelência, disseminar a educação fiscal com clareza e torna-se um profissional que atende às exigências do mercado de trabalho. Nos treinamentos, os extensionistas ampliaram suas relações interpessoais, pois ocorreram atividades em grupo, que incluíam integrantes tanto da mesma equipe como também de outros NAFs. O relacionamento interpessoal é primordial para o desempenho e desenvolvimento dos colaboradores nas organizações, pois nesse ambiente faz-se necessário influenciar os demais, conquistar seguidores e aumentar o networking (DEMETRIO, 2017). Com a pandemia do novo Corona Vírus, os alunos tiveram de se adaptar aos meios de comunicação digital. Isso já é uma oportunidade de se familiarizar com as ferramentas tecnológicas, sendo considerada uma habilidade necessária para o desempenho da função do contador. Agnolin (2017) afirma que devido à grande demanda de obrigações acessórias e clientes com as mais diversas particularidades, os escritórios de contabilidade precisam estar sempre atualizados perante os avanços tecnológicos. De forma direta foram beneficiadas 696 contribuintes e, de forma indireta, o triplo dessa quantidade. Essas pessoas que foram beneficiadas de forma indireta, foram por intermédio dos que receberam os serviços diretamente, pois a partir disso tornaram-se multiplicadores, transmitindo esses conhecimentos para familiares, amigos e vizinhos. Dessa maneira, isso traz grande benefício para alguns órgãos 
públicos, como a Receita Federal do Brasil, Secretaria da Fazenda do Ceará e Caixa Econômica Federal, visto que diminui a concentração de pessoas nas filas, principalmente, em tempos de pandemia que deve-se evitar aglomerações. Com isso, a sociedade também é beneficiada, pois obtém o atendimento mais ágil e, prezando ainda mais, pela saúde. Como também a universidade, que cumpre com seu papel social, em virtude de estar prestando serviços a sociedade.

\section{CONCLUSÕES}

Observa-se que o projeto é de suma importância para a sociedade, os alunos, a Receita Federal e a instituição de ensino. A sociedade com baixa renda recebe os serviços gratuitamente e obtém conhecimentos fiscais; os alunos tornam-se profissionais mais qualificados; a Receita Federal do Brasil propaga a educação fiscal e a instituição de ensino formam profissionais melhores. Assim, atingindo os objetivos gerais e específicos. Pode-se observar também, o quão importante é a extensão universitária para a formação de profissionais melhores, pois é a partir de vivências como essa, que os alunos adquirem uma alta carga de experiência e conhecimento para entrar no mercado de trabalho bem mais preparado. Dessa maneira, atendendo às exigências que lhe são impostas.

\section{AGRADECIMENTOS}

A Pró-Reitoria de Extensão da Universidade Federal do Cariri (PROEX/UFCA) pela concessão de bolsa e ao professor coordenador do projeto Ricardo Aladim Monteiro pela orientação e incentivo dado.

\section{FONTES DE FINANCIAMENTO}

A Pró-Reitoria de Extensão da Universidade Federal do Cariri (PROEX/UFCA) pela concessão de bolsa a autora.

\section{REFERÊNCIAS}

AGNOLIN, Tatiane Daniela. A importância da tecnologia da informação na contabilidade: um estudo em uma empresa de prestação de serviços contábeis em Caxias do Sul - RS. 2017. Trabalho de Conclusão de Curso (Bacharelado em Ciências Contábeis) - Universidade de Caxias do Sul, Caxias do Sul, 2008.

BRASIL. A Cidadania Fiscal na Receita Federal. Disponível em: <http://receita.economia.gov.br/acessorapido/direitos-e-deveres/educacao-fiscal/a-educacao-fiscal-na-receita-federal>. Acesso em 17 Jun. 2020.

BRASIL. Educação Fiscal. Disponível em: <http://receita.economia.gov.br/acesso-rapido/direitos-e-deveres/ educacao-fiscal>. Acesso em: 17 Set. 2020.

CAIXAECONÔMICAFEDERAL. Auxílio Emergencial do Governo Federal. Disponível em: <https:// auxilio.caixa.gov.br/\#/inicio>. Acesso em: 04 Ago. 2020. 
DEMETRIO, Vanessa Lima. A importância do relacionamento interpessoal no ambiente de trabalho, liderança. Disponível em: <https://www.webartigos.com/artigos/a-importancia-do-relacionamentointerpessoal-no-ambiente-de-trabalho-lideranca/118344>. Acesso em: 08 Set. 2020.

GRZYBOVSKI, Denize; HAHN, Tatiana Gaertner. Educação fiscal: premissa para melhor percepção da questão tributária. Revista de Administração Pública, Rio de Janeiro, v. 40, n. 5, p. 841-864, 2006.

LOYOLA, Micheli Franzoni de; PAIVA, Emílio. A importância da comunicação entre líderes e liderados. Memorial TCC - Caderno da Graduação, [s. 1.], v. 3, n. 1, p. 239-255, 2017.

MOREIRA, Josicleide de Amorim Pereira; VIEIRA, Maria das Graças; SILVA, Cristiane Gomes da. Entre a Teoria, a Prática e a Tecnologia: Relação entre o Saber Teórico e o Saber Prático no Contexto da Formação Contábil e o Pensamento de Jüngen Habermas. Brazilian Business Review, v. 12, n. 4, p. 130-148, 2015.

SILVA KOGLIN, Terena Souza da; OLIVEIRA KOGLIN, João Carlos de. A importância da extensão nas universidades brasileiras e a transição do reconhecimento ao descaso. Revista Brasileira de Extensão Universitária, [s. 1.], v. 10, n. 2, p. 71-78, 2019.

SOUZA, Eliene Costa de; SOUSA, Sara Neris; SILVA, Anderson Roberto Pires e; GONÇALVES, Tadeu Junior de Castro. As características qualitativas da informação contábil a partir da percepção dos profissionais de contabilidade. Anais do XII Congresso UFPE de Ciências Contábeis, [s. 1.], v. 3, p. 1-17, 2018.

UFCAitinerante. Disponível em: <https://www.ufca.edu.br/academico/extensao/ufca-itinerante/>. Acesso em: 05 Ago. 2020.

Submetido em: 22/12/2020. Aceito em: 04/03/2021. 